\title{
An anterior cruciate ligament injury does not affect the neuromuscular function of the non-injured leg except for dynamic balance and voluntary quadriceps activation
}

\author{
Tjerk Zult ${ }^{1} \cdot$ Alli Gokeler $^{1} \cdot$ Jos J. A. M. van Raay ${ }^{2} \cdot$ Reinoud W. Brouwer $^{2}$ • \\ Inge Zijdewind ${ }^{3} \cdot$ Tibor Hortobágyi $^{1}$
}

Received: 11 May 2016 / Accepted: 16 September 2016 / Published online: 24 September 2016

(c) The Author(s) 2016. This article is published with open access at Springerlink.com

\begin{abstract}
Purpose The function of the anterior cruciate ligament (ACL) patients' non-injured leg is relevant in light of the high incidence of secondary ACL injuries on the contralateral side. However, the non-injured leg's function has only been examined for a selected number of neuromuscular outcomes and often without appropriate control groups. We measured a broad array of neuromuscular functions between legs of ACL patients and compared outcomes to age, sex, and physical activity matched controls.

Methods Thirty-two ACL-deficient patients (208 \pm 145 days post-injury) and active and less-active controls ( $N=20$ each) participated in the study. We measured single- and multi-joint neuromuscular function in both legs in each group and expressed the overall neuromuscular function in each leg by calculating a mean z-score across all neuromuscular measures. A group by leg MANOVA and ANOVA were performed to examine group and leg differences for the selected outcomes.

Results After an ACL injury, duration (-4.3 h/week) and level (Tegner activity score of -3.9) of sports activity decreased and was comparable to less-active controls. ACL patients showed bilateral impairments in the star excursion balance test compared to both control groups $(P \leq 0.004)$
\end{abstract}

Tjerk Zult

t.d.zult@umcg.nl

1 Center for Human Movement Sciences, University of Groningen, University Medical Center Groningen, A. Deusinglaan 1, 9700 AD Groningen, The Netherlands

2 Department of Orthopedic Surgery, Martini Hospital, Groningen, The Netherlands

3 Department of Neuroscience, University of Groningen, University Medical Center Groningen, Groningen, The Netherlands and for central activation ratio compared to active controls $(P \leq 0.002)$. There were between-leg differences within each group for maximal quadriceps and hamstring strength, voluntary quadriceps activation, star excursion balance test performance, and single-leg hop distance (all $P<0.05$ ), but there were no significant differences in quadriceps force accuracy and variability, knee joint proprioception, and static balance. Overall neuromuscular function (mean z-score) did not differ between groups, but ACL patients' non-injured leg displayed better neuromuscular function than the injured leg $(P<0.05)$.

Conclusions Except for poorer dynamic balance and reduced quadriceps activation, ACL patients had no bilateral neuromuscular deficits despite reductions in physical activity after injury. Therapists can use the non-injured leg as a reference to assess the injured leg's function for tasks measured in the present study, excluding dynamic balance and quadriceps activation. Rehabilitation after an ACL injury should be mainly focused on the injured leg.

Level of evidence III.

Keywords ACL deficient · Bilateral impairment · Force accuracy $\cdot$ Force variability $\cdot$ Maximal voluntary force . Postural balance $\cdot$ Proprioception $\cdot$ Twitch interpolation

\section{Introduction}

An injury to the anterior cruciate ligament (ACL) compromises not only the injured but presumably also the non-injured limb's function. Quadriceps weakness [31], impaired ability to fully activate the quadriceps muscle [43, 44], and difficulty in maintaining single-leg balance [34] can be present in both legs after an ACL injury up to even 2 years after reconstruction [16]. The function of 
the non-injured leg after the first ACL injury is clinically important because $8 \%$ of the ACL reconstructed patients suffer a subsequent ACL injury to the non-injured leg, with an even higher risk for patients younger than 25 years (11\%) [48]. However, a comprehensive characterization of the non-injured leg's neuromuscular function is lacking.

The non-injured leg is often used as a reference for the neuromuscular function of the injured leg, but it is likely that the neuromuscular deficit is underestimated if the status of the non-injured leg is also compromised [30, 35]. To determine the functional deficit in the non-injured leg after an ACL injury, it would be necessary to compare patient outcomes to an age, sex, and physical activity matched control group. In studies on ACL injuries, the physical activity level of control participants is often matched to the preinjury activity level of ACL patients [31]. However, since the amount of physical activity decreases following the injury ACL patients' leg function should be more appropriately compared against a less-active control group matched to the ACL patients' post-injury activity level.

Quantifying the magnitude and nature of any neuromuscular deficit in the non-injured leg after an ACL injury is important because it can shed light on the neuromuscular scope of the injury, reduce the risk of a contralateral ACL injury if deficits are treated adequately, and inform therapists' decision to treat the non-injured leg. Unfortunately, previous research has examined neuromuscular deficits in the non-injured leg for only a few neuromuscular measures (i.e. quadriceps strength, voluntary quadriceps activation, single-leg balance) $[31,34,43,44]$. Therefore, the purpose of this study was to compare a broad array of neuromuscular measurements carried out on ACL patients' injured and non-injured leg and compare these to the legs of active and less-active controls, while controlling for age, sex, and physical activity. The ACL patients' non-injured leg was expected to demonstrate impaired neuromuscular function compared with active but not less-active controls. The largest decline in neuromuscular function was still expected to occur in ACL patients' injured leg.

\section{Materials and methods}

\section{Participants}

Table 1 shows the group characteristics of the ACL-deficient patients awaiting surgery (16 men, 16 women) and healthy volunteers (20 men, 20 women). Patient inclusion criteria were: age 18-30 years, unilateral ACL tear with/without partial meniscal resection, and time between ACL injury and testing $<2$ year. Patient exclusion criteria were: previous ACL reconstruction, history of a lower limb injury that required surgery, pregnancy, current or prior neurological conditions. Controls were between age 18-30 years and had no history of orthopaedic, cardiovascular, neurological, and cognitive impairments. Controls were recruited via ads on social media, where we specifically asked for active and sedentary persons. After recruitment, controls were subdivided into an active and lessactive group based on the physical activity level (i.e. hours spent on sport per week). The ten most active men and women were allocated to the active group, and the ten least active men and women were allocated to the less-active group. We have also quantified the level of physical activity through the Tegner activity score [42]. Leg dominance was determined using the Waterloo Footedness Questionnaire [12].

\section{General experimental protocol}

As a warm-up, each participant started with 5 min of cycling on a bicycle ergometer. Next, maximal knee flexor and extensor strength, quadriceps force accuracy and variability, knee joint proprioception, voluntary quadriceps activation, static and dynamic balance, and single-leg hop distance were measured. Every participant performed every test with each leg randomized between legs.

\section{Maximal voluntary contraction (MVC)}

Following strictly the manufacturer's guidelines and our own previous protocols, we have measured isometric and dynamic (concentric and eccentric) quadriceps and hamstring MVCs on an isokinetic dynamometer (Biodex Medical Systems, Shirley, NY, USA) [7, 10, 11, 17, 27, 28]. Participants' knee range of motion for the concentric and eccentric contractions was set between $0^{\circ}$ (full knee extension) and $90^{\circ}$ of knee flexion. After a thorough familiarization with the contraction conditions, participants performed three isometric MVCs at $65^{\circ}$ of knee flexion [28], three eccentric MVCs at $60 \%$ s, and six concentric MVCs each at 60,120 , and $180 \%$ s. There was a 1 -min pause between conditions. The order of quadriceps and hamstring contractions and the order of isometric and dynamic MVCs were alternated between participants. The peak torque value, normalized to body weight, was used in the statistical analysis.

\section{Voluntary quadriceps activation}

Quadriceps activation was assessed with twitch interpolation and the central activation ratio (CAR) during isometric contractions [5, 31, 43, 44]. Participants were strapped to the seat of a custom-built dynamometer [46], with the hips and knees in $90^{\circ}$ flexion and the arms folded in front of the chest. We have stimulated the quadriceps through two $10 \times 14 \mathrm{~cm}$ aluminium foil electrodes, covered with 


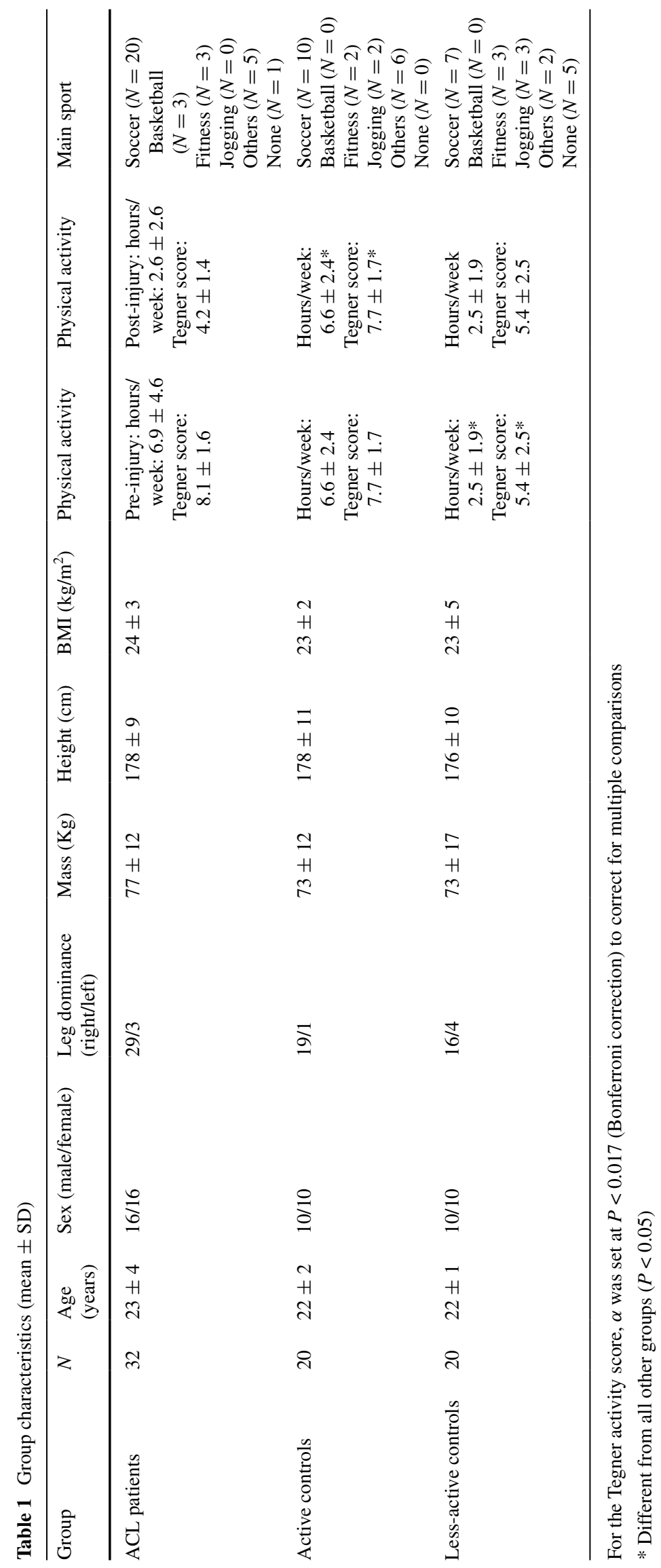


Fig. 1 Voluntary quadriceps activation determined for a single subject using linear regression equation $(y=-0.56 x+85.11$; $R=-0.96)$. The open circles represent the four data points used for calculating the linear regression equation. Intersection point with the $x$-axis is the estimated maximal torque (151.3 Nm, filled circle). Intersection point with the $y$-axis using the maximal quadriceps torque is the estimated quadriceps activation $(-25.9 \%$, filled triangle). Note the estimated maximal torque underestimates the produced maximal torque (197.3 Nm, filled square)

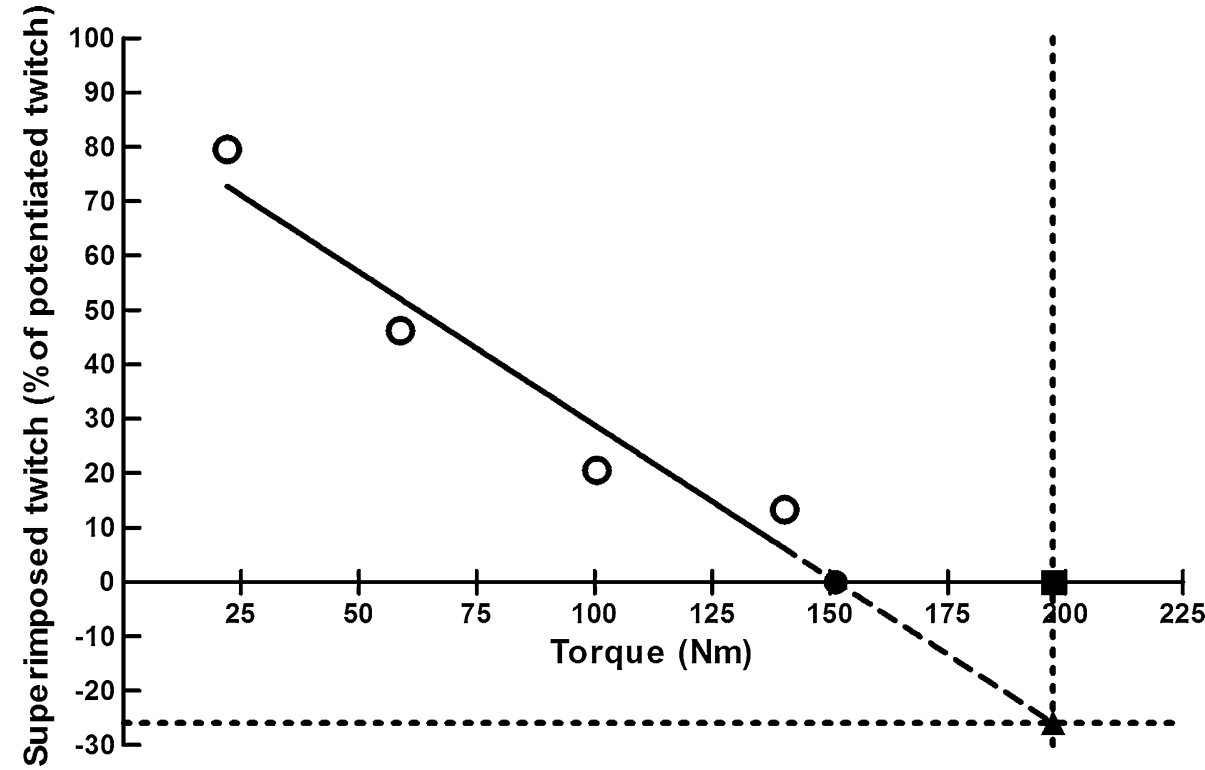

water-soaked sponges (cathode: middle of rectus femoris, anode: distal $10 \mathrm{~cm}$ above patella), connected to a highvoltage stimulator (Digitimer DS7AH, Welwyn Garden City, UK) that discharged two pulses $10 \mathrm{~ms}$ apart (200- $\mu \mathrm{s}$ pulse, $100 \mathrm{~Hz}$ ). We refer to the force evoked by a doublet as a twitch. The torque signal was amplified, sampled at $500 \mathrm{~Hz}$ (CED Power 1401 Plus; Cambridge Electronic Design, Cambridge, UK), visually inspected on a monitor, and recorded and offline-analysed by software (Spike 2, version 5.21). The protocol consisted of: 1 . Three isometric quadriceps MVCs; 2. Maximal twitch torque determination during contractions at $10 \%$ MVC (to remove slack); 3. Superimposed twitches at 30, 50, 75, and $100 \%$ of MVC; 4. Two twitches at rest from which the higher of the two was classified as potentiated twitch.

At 10, 30, 50, and $75 \%$ of MVC, we have computed a ratio as: (superimposed twitch/potentiated twitch) $* 100 \%$. The ratio for each contraction intensity was plotted against the respective force upon which the twitch was superimposed. A linear regression equation $(y=a x+b)$ was then generated for each participant to determine the estimated maximal force and voluntary muscle activation (Fig. 1). The estimated maximal force was determined by calculating the intersection point with the $x$-axis, and voluntary activation was derived by determining the intersection point with the $y$-axis using the actual MVC torque [5]. The CAR was calculated as: MVC/(MVC + superimposed twitch) $* 100 \%$.

\section{Force accuracy and variability}

Participants have matched the produced torque as steadily and accurately as possible with the target torque displayed as a horizontal line on the monitor set to $20 \%$ of MVC for the isometric trials and to $40 \mathrm{Nm}$ for the dynamic trials [27, 28]. After familiarization, participants performed three isometric trials at $65^{\circ}$ of knee flexion (5-s duration) and four concentric and eccentric trials at $20^{\circ}$ s between $90^{\circ}$ and $10^{\circ}$ of knee flexion. The order of dynamic and isometric contractions was rotated between participants. Force accuracy and variability were computed in the final 3-s portion of the data for isometric trials and the middle 2-s portion for dynamic trials. Force accuracy was the absolute difference between the produced torque and the target torque. Force variability was the coefficient of variation (i.e. SD of the produced force divided by the mean force). Force accuracy and force variability were calculated for each data point, and the average across the trials was used in the statistical analysis.

\section{Knee joint proprioception}

Knee joint proprioception was measured, in a random order, at $15,30,45$, and $60^{\circ}$ of knee flexion using a joint repositioning task [27]. Knee joint proprioception was computed as the absolute difference between the actual leg position and the target position and was expressed in degrees.

\section{Static balance}

Static balance was measured using the one-leg standing balance test, starting with eyes-open followed by eyesclosed condition [2]. The maximum score that participants could obtain was $60 \mathrm{~s}$. The best score of the two trials was used in the statistical analysis. 


\section{Dynamic balance}

The star excursion balance test (SEBT) was used to assess dynamic balance [19]. The normalized scores from the eight directions were averaged to create a composite score used for the statistical analysis. After 5-min of rest, the measurement continued with the other leg as the stance leg.

\section{Single-leg hop test}

Participants performed the single-leg hop test for distance, allowing the use of the arms to accelerate [9]. The hop distance was measured from the toe at push-off to the heel where the participant landed. The maximal hop distance was used in the analysis. All participants provided written informed consent to the experimental procedures, which were approved by the medical ethics committee of the University Medical Center Groningen (ID 2012.362) and in accordance with the Declaration of Helsinki.

\section{Statistical analyses}

Data in the text and figures are presented as mean $\pm \mathrm{SD}$ (SPSS version 22). Each variable was checked for normality. A one-way ANOVA was used to test for differences between groups in age, mass, height, BMI, and the amount of physical activity. Between-group differences in sex and Tegner activity score were tested using, respectively, a Chi-square and a Kruskal-Wallis test. A group (3) by leg (2) MANOVA was performed to test the between-leg differences in quadriceps MVCs (5 conditions), hamstring MVCs (5 conditions), voluntary quadriceps activation (5 conditions), force accuracy (3 conditions), force variability (3 conditions), proprioception ( 4 conditions), and static balance ( 2 conditions). Pillai's Trace was used to determine between- and within-subject effects. A significant MANOVA was followed up by univariate ANOVAs. Dynamic balance and single-leg hop distance were analysed using a group by leg one-way ANOVA. In addition, we converted the outcome on every neuromuscular measure to a $z$-score. The $z$-scores were averaged per neuromuscular function (i.e. quadriceps MVCs, hamstring MVCs, voluntary quadriceps activation, force accuracy, force variability, proprioception, static balance, dynamic balance, and single-leg hop distance), and a mean $z$-score calculated across these nine functions was used to test the overall difference in neuromuscular function between legs. Significant $F$ values from the ANOVA's were subjected to a Tukey HSD post hoc pairwise comparison to determine the means that were different. The level of significance $(\alpha)$ was set at $P<0.05$.

The sample size was based on a previous study reporting bilateral impairments in quadriceps strength and activation in ACL-deficient patients [31]. About $50 \%$ more ACL-deficient patients were included compared to Lepley et al. [31], because our ACL patients would be less homogeneous with regard to the time since injury.

\section{Results}

\section{Group characteristics}

ACL-deficient patients were all recreational athletes, and 29 of 32 sustained a non-contact ACL injury, ruptured the ACL on the non-dominant side $(N=17)$, and reported relatively few knee complaints on a visual analogue scale (mean $28 \pm 15,0$ no and 100 severe pain) [14]. The time between injury and testing was $208 \pm 145$ days (range 60-664 days) and between testing and surgery was $23 \pm 17$ days (range 2-62 days).

Table 1 shows the group characteristics. The groups did not differ in age, sex, mass, height, BMI, or leg dominance (all n.s.). Less-active controls had a lower Tegner score and a shorter duration of sport participation per week than ACL patients prior to injury and active controls $(P<0.01)$. In addition, these two variables were, respectively, 61 and $45 \%$ lower for ACL patients after injury compared to active controls $(P<0.001)$.

\section{Single-joint neuromuscular function}

Table 2 shows the static and dynamic quadriceps MVCs. The MANOVA showed a leg $\left(F_{5,65}=8.4, P<0.001\right)$ and a group by leg interaction effect $\left(F_{10,132}=3.9, P<0.001\right)$. Follow-up of univariate ANOVAs showed an interaction effect for all five MVC conditions (all $P \leq 0.018$ ) caused by the greater between-leg differences in ACL patients than controls.

The MANOVA for hamstring MVCs showed a leg main effect $\left(F_{5,65}=3.3, P=0.010\right)$ and a group by leg interaction $\left(F_{10,132}=2.5, P=0.010\right)$. Follow-up by univariate ANOVAs showed an interaction effect for eccentric and isometric contractions $(P \leq 0.033)$ caused by the greater between-leg difference in ACL patients versus controls (Table 2).

Table 3 shows the voluntary quadriceps activation data. The MANOVA for quadriceps activation revealed a between-group difference $\left(F_{10,132}=2.1, P=0.028\right)$, a leg main effect $\left(F_{5,65}=3.3, P=0.011\right)$, and a group by leg interaction $\left(F_{10,132}=3.1, P=0.001\right)$. CAR in ACL patients was lower than in active controls $(P=0.002)$, and there was a greater between-leg difference in ACL patients versus controls for isometric MVCs and estimated maximal force. 
Table 2 Maximal voluntary contraction data of both legs of ACL-deficient patients and active and less-active controls (mean \pm SD)

\begin{tabular}{|c|c|c|c|c|c|}
\hline \multirow[t]{2}{*}{ Variables } & \multirow[t]{2}{*}{ Group } & \multirow{2}{*}{$\begin{array}{l}\text { Non-injured leg/ } \\
\text { dominant leg }\end{array}$} & \multirow{2}{*}{$\begin{array}{l}\text { Injured leg/ } \\
\text { non-dominant leg }\end{array}$} & \multicolumn{2}{|l|}{ Difference } \\
\hline & & & & Absolute & Percentage \\
\hline \multicolumn{6}{|l|}{ Quadriceps (Nm/kg) } \\
\hline \multirow[t]{3}{*}{ Eccentric $60^{\circ} / \mathrm{s}$} & ACL patients & $3.6 \pm 0.8$ & $3.1 \pm 0.8$ & $0.5^{\dagger}$ & 13.9 \\
\hline & Active controls & $4.0 \pm 1.0$ & $3.6 \pm 0.8$ & $0.4^{\dagger}$ & 10.0 \\
\hline & Less-active controls & $3.5 \pm 0.9$ & $3.5 \pm 1.0$ & 0.0 & 0.0 \\
\hline \multirow[t]{3}{*}{ Isometric } & ACL patients & $3.5 \pm 0.7$ & $3.1 \pm 0.8$ & $0.4^{\dagger}$ & 11.4 \\
\hline & Active controls & $3.7 \pm 0.6$ & $3.6 \pm 0.7$ & 0.1 & 2.7 \\
\hline & Less-active controls & $3.4 \pm 0.7$ & $3.2 \pm 0.8$ & $0.2^{\dagger}$ & 5.9 \\
\hline \multirow[t]{3}{*}{ Concentric $60^{\circ} / \mathrm{s}$} & ACL patients & $2.5 \pm 0.6$ & $2.2 \pm 0.6$ & $0.3^{\dagger}$ & 12.0 \\
\hline & Active controls & $2.6 \pm 0.6$ & $2.6 \pm 0.5$ & 0 & 0.0 \\
\hline & Less-active controls & $2.5 \pm 0.6$ & $2.4 \pm 0.6$ & $0.1^{\dagger}$ & 4.0 \\
\hline \multirow[t]{3}{*}{ Concentric $120 \%$ s } & ACL patients & $2.1 \pm 0.5$ & $1.9 \pm 0.5$ & $0.2^{\dagger}$ & 9.5 \\
\hline & Active controls & $2.1 \pm 0.5$ & $2.2 \pm 0.4$ & -0.1 & -4.8 \\
\hline & Less-active controls & $2.0 \pm 0.5$ & $1.9 \pm 0.5$ & 0.1 & 5.0 \\
\hline \multirow[t]{3}{*}{ Concentric $180^{\circ} / \mathrm{s}$} & ACL patients & $1.9 \pm 0.5$ & $1.7 \pm 0.4$ & $0.2^{\dagger}$ & 10.5 \\
\hline & Active controls & $1.8 \pm 0.5$ & $1.9 \pm 0.4$ & -0.1 & -5.6 \\
\hline & Less-active controls & $1.9 \pm 0.5$ & $1.7 \pm 0.4$ & $0.2^{\dagger}$ & 10.5 \\
\hline \multicolumn{6}{|l|}{ Hamstring $(\mathrm{Nm} / \mathrm{kg})$} \\
\hline \multirow[t]{3}{*}{ Eccentric $60^{\circ} / \mathrm{s}$} & ACL patients & $2.4 \pm 0.5$ & $2.0 \pm 0.5$ & $0.4^{\dagger}$ & 16.7 \\
\hline & Active controls & $2.4 \pm 0.4$ & $2.4 \pm 0.5$ & 0.0 & 0.0 \\
\hline & Less-active controls & $2.5 \pm 0.6$ & $2.3 \pm 0.6$ & 0.2 & 8.0 \\
\hline \multirow[t]{3}{*}{ Isometric } & ACL patients & $1.5 \pm 0.3$ & $1.4 \pm 0.4$ & $0.1^{\dagger}$ & 6.7 \\
\hline & Active controls & $1.6 \pm 0.4$ & $1.6 \pm 0.4$ & 0.0 & 0.0 \\
\hline & Less-active controls & $1.5 \pm 0.3$ & $1.5 \pm 0.4$ & 0.0 & 0.0 \\
\hline \multirow[t]{3}{*}{ Concentric $60 \%$} & ACL patients & $1.3 \pm 0.3$ & $1.2 \pm 0.3$ & 0.1 & 7.7 \\
\hline & Active controls & $1.4 \pm 0.4$ & $1.4 \pm 0.3$ & 0.0 & 0.0 \\
\hline & Less-active controls & $1.2 \pm 0.3$ & $1.2 \pm 0.4$ & 0.0 & 0.0 \\
\hline \multirow[t]{3}{*}{ Concentric $120^{\circ} / \mathrm{s}$} & ACL patients & $1.1 \pm 0.3$ & $1.1 \pm 0.3$ & 0.0 & 0.0 \\
\hline & Active controls & $1.3 \pm 0.4$ & $1.2 \pm 0.3$ & 0.1 & 7.7 \\
\hline & Less-active controls & $1.1 \pm 0.2$ & $1.1 \pm 0.3$ & 0.0 & 0.0 \\
\hline \multirow[t]{3}{*}{ Concentric $180^{\circ} / \mathrm{s}$} & ACL patients & $1.1 \pm 0.3$ & $1.1 \pm 0.2$ & 0.0 & 0.0 \\
\hline & Active controls & $1.2 \pm 0.3$ & $1.2 \pm 0.4$ & 0.0 & 0.0 \\
\hline & Less-active controls & $1.0 \pm 0.3$ & $1.0 \pm 0.3$ & 0.0 & 0.0 \\
\hline
\end{tabular}

$\dagger$ Between-leg difference within each group $(P<0.05)$

MANOVAs did not show any statistical effects in quadriceps force accuracy and variability and knee joint proprioception (all n.s., Table 3).

\section{Multi-joint neuromuscular function}

Table 4 shows the multi-joint neuromuscular data. The MANOVA showed no effects for static balance (all n.s.). The ANOVA for dynamic balance revealed a group effect $\left(F_{2,69}=9.0, P<0.001\right)$ and group by leg interaction $\left(F_{2,69}=6.0, P=0.004\right)$. Dynamic balance in ACL patients was poorer compared with controls $(P \leq 0.004)$ and showed a greater between-leg difference in ACL patients and less-active controls than active controls. The ANOVA for single-leg hop distance showed a group by leg interaction $\left(F_{2,69}=11.4\right.$, $P<0.001)$; between-leg differences were greater for ACL patients and less-active controls than active controls.

\section{Overall index of neuromuscular leg function}

Figure 2 illustrates the group by leg interaction effect for overall neuromuscular function $\left(F_{2,69}=7.0, P=0.002\right)$ caused by better overall neuromuscular function in the noninjured leg $(P<0.05)$. 
Table 3 Single-joint neuromuscular data of both legs of ACL-deficient patients and active and less-active controls (mean \pm SD)

\begin{tabular}{|c|c|c|c|c|c|}
\hline \multirow[t]{2}{*}{ Variables } & \multirow[t]{2}{*}{ Group } & \multirow{2}{*}{$\begin{array}{l}\text { Non-injured leg/ } \\
\text { dominant leg }\end{array}$} & \multirow{2}{*}{$\begin{array}{l}\text { Injured leg/ } \\
\text { non-dominant leg }\end{array}$} & \multicolumn{2}{|l|}{ Difference } \\
\hline & & & & Absolute & Percentage \\
\hline \multicolumn{6}{|c|}{ Quadriceps voluntary force and muscle activation } \\
\hline \multirow[t]{3}{*}{$\operatorname{CAR}(\%)^{*}$} & ACL patients & $96.6 \pm 2.6$ & $95.7 \pm 3.2$ & 0.9 & 0.9 \\
\hline & Active controls & $98.2 \pm 1.7$ & $98.4 \pm 1.4$ & -0.2 & -0.2 \\
\hline & Less-active controls & $96.8 \pm 2.0$ & $97.1 \pm 2.0$ & -0.3 & -0.3 \\
\hline \multirow[t]{3}{*}{ Isometric MVC (Nm) } & ACL patients & $206.6 \pm 70.3$ & $183.6 \pm 74.3$ & $23.0^{\dagger}$ & 11.1 \\
\hline & Active controls & $191.3 \pm 62.3$ & $204.7 \pm 73.7$ & $-13.4^{\dagger}$ & -7.0 \\
\hline & Less-active controls & $190.2 \pm 66.2$ & $190.8 \pm 71.6$ & -0.6 & -0.3 \\
\hline \multirow[t]{3}{*}{ Estimated MVC (Nm) } & ACL patients & $160.8 \pm 54.0$ & $142.6 \pm 55.2$ & $18.2^{\dagger}$ & 11.3 \\
\hline & Active controls & $144.9 \pm 48.5$ & $153.6 \pm 53.3$ & $-8.7^{\dagger}$ & -6.0 \\
\hline & Less-active controls & $141.9 \pm 48.1$ & $148.3 \pm 54.2$ & -6.4 & -4.5 \\
\hline \multirow[t]{3}{*}{ Potentiated doublet force $(\mathrm{Nm})$} & ACL patients & $81.6 \pm 26.1$ & $72.7 \pm 25.6$ & 8.9 & 10.9 \\
\hline & Active controls & $74.8 \pm 21.5$ & $73.1 \pm 22.1$ & 1.7 & 2.3 \\
\hline & Less-active controls & $81.7 \pm 26.7$ & $73.7 \pm 24.3$ & 8.0 & 9.8 \\
\hline \multirow[t]{3}{*}{ Activation ( $\%$ of potentiated twitch) } & ACL patients & $-24.3 \pm 12.3$ & $-24.7 \pm 11.7$ & -0.4 & 1.6 \\
\hline & Active controls & $-28.6 \pm 9.3$ & $-29.5 \pm 7.0$ & -0.9 & 3.1 \\
\hline & Less-active controls & $-28.8 \pm 7.6$ & $-27.5 \pm 8.2$ & 1.3 & -4.5 \\
\hline \multicolumn{6}{|l|}{ Force accuracy $(\mathrm{Nm})^{\mathrm{a}}$} \\
\hline \multirow[t]{3}{*}{ Eccentric } & ACL patients & $12.1 \pm 5.7$ & $12.7 \pm 5.3$ & -0.6 & -5.0 \\
\hline & Active controls & $9.7 \pm 4.3$ & $10.1 \pm 3.9$ & -0.4 & -4.1 \\
\hline & Less-active controls & $12.3 \pm 5.7$ & $12.0 \pm 5.8$ & 0.3 & 2.4 \\
\hline \multirow[t]{3}{*}{ Isometric } & ACL patients & $2.4 \pm 2.1$ & $2.8 \pm 4.5$ & -0.4 & -16.7 \\
\hline & Active controls & $2.0 \pm 1.9$ & $2.0 \pm 1.3$ & 0.0 & 0.0 \\
\hline & Less-active controls & $2.3 \pm 2.0$ & $2.4 \pm 2.2$ & -0.1 & -4.3 \\
\hline \multirow[t]{3}{*}{ Concentric } & ACL patients & $10.9 \pm 6.7$ & $9.5 \pm 6.9$ & 1.4 & 12.8 \\
\hline & Active controls & $7.6 \pm 5.1$ & $7.3 \pm 3.2$ & 0.3 & 3.9 \\
\hline & Less-active controls & $9.2 \pm 5.6$ & $9.6 \pm 6.8$ & -0.4 & -4.3 \\
\hline \multicolumn{6}{|l|}{ Force variability ( $\%$ of mean force $)^{\mathrm{b}}$} \\
\hline \multirow[t]{3}{*}{ Eccentric } & ACL patients & $21.0 \pm 11.0$ & $26.6 \pm 16.7$ & -5.6 & -26.7 \\
\hline & Active controls & $20.0 \pm 10.3$ & $20.7 \pm 7.5$ & -0.7 & -3.5 \\
\hline & Less-active controls & $24.0 \pm 10.1$ & $24.3 \pm 11.1$ & -0.3 & -1.3 \\
\hline \multirow[t]{3}{*}{ Isometric } & ACL patients & $3.4 \pm 2.6$ & $4.6 \pm 7.2$ & -1.2 & -35.3 \\
\hline & Active controls & $2.7 \pm 1.1$ & $3.0 \pm 1.2$ & -0.3 & -11.1 \\
\hline & Less-active controls & $4.0 \pm 2.6$ & $3.8 \pm 2.4$ & 0.2 & 5.0 \\
\hline \multirow[t]{3}{*}{ Concentric } & ACL patients & $18.8 \pm 8.9$ & $18.8 \pm 9.0$ & 0.0 & 0.0 \\
\hline & Active controls & $15.7 \pm 11.3$ & $16.5 \pm 7.0$ & -0.8 & -5.1 \\
\hline & Less-active controls & $15.6 \pm 7.5$ & $17.3 \pm 10.1$ & -1.7 & -10.9 \\
\hline \multicolumn{6}{|l|}{ Proprioception $\left({ }^{\circ}\right)^{\mathrm{c}}$} \\
\hline \multirow[t]{3}{*}{$15^{\circ}$} & ACL patients & $3 \pm 2$ & $3 \pm 3$ & 0 & 0 \\
\hline & Active controls & $4 \pm 3$ & $5 \pm 3$ & -1 & 25.0 \\
\hline & Less-active controls & $4 \pm 3$ & $6 \pm 5$ & -2 & -50.0 \\
\hline \multirow[t]{3}{*}{$30^{\circ}$} & ACL patients & $4 \pm 3$ & $3 \pm 3$ & 1 & 25.0 \\
\hline & Active controls & $4 \pm 3$ & $3 \pm 2$ & 1 & 25.0 \\
\hline & Less-active controls & $4 \pm 3$ & $3 \pm 2$ & 1 & 25.0 \\
\hline $45^{\circ}$ & ACL patients & $3 \pm 3$ & $4 \pm 3$ & -1 & -33.3 \\
\hline & Active controls & $3 \pm 3$ & $4 \pm 2$ & -1 & -33.3 \\
\hline & Less-active controls & $4 \pm 3$ & $4 \pm 3$ & 0 & 0.0 \\
\hline
\end{tabular}


Table 3 continued

\begin{tabular}{|c|c|c|c|c|c|}
\hline \multirow[t]{2}{*}{ Variables } & \multirow[t]{2}{*}{ Group } & \multirow{2}{*}{$\begin{array}{l}\text { Non-injured leg/ } \\
\text { dominant leg }\end{array}$} & \multirow{2}{*}{$\begin{array}{l}\text { Injured leg/ } \\
\text { non-dominant leg }\end{array}$} & \multicolumn{2}{|l|}{ Difference } \\
\hline & & & & Absolute & $\overline{\text { Percentage }}$ \\
\hline \multirow[t]{3}{*}{$60^{\circ}$} & ACL patients & $3 \pm 2$ & $3 \pm 2$ & 0 & 0.0 \\
\hline & Active controls & $4 \pm 3$ & $4 \pm 3$ & 0 & 0.0 \\
\hline & Less-active controls & $4 \pm 2$ & $3 \pm 2$ & 1 & 25.0 \\
\hline
\end{tabular}

$C A R$ central activation ratio

$*$ Between-group difference $(P<0.05)$

$\dagger$ Between-leg difference within each group $(P<0.05)$

${ }^{\text {a }}$ Force accuracy is expressed as the absolute difference between the produced force and the target force

${ }^{\mathrm{b}}$ Force variability was quantified by the SD of the produced force divided by the mean force (i.e. coefficient of variation)

${ }^{c}$ Proprioception is expressed as the absolute error relative to the target position

Table 4 Multi-joint neuromuscular data of both legs of ACL-deficient patients and active and less-active controls (mean \pm SD)

\begin{tabular}{|c|c|c|c|c|c|}
\hline \multirow[t]{2}{*}{ Variables } & \multirow[t]{2}{*}{ Group } & \multirow{2}{*}{$\begin{array}{l}\text { Non-injured leg/ } \\
\text { dominant leg }\end{array}$} & \multirow{2}{*}{$\begin{array}{l}\text { Injured leg/ } \\
\text { non-dominant leg }\end{array}$} & \multicolumn{2}{|l|}{ Difference } \\
\hline & & & & Absolute & Percentage \\
\hline \multirow{3}{*}{$\begin{array}{l}\text { One-leg standing balance test, eyes } \\
\text { open (s) }\end{array}$} & ACL patients & $60 \pm 0$ & $60 \pm 0$ & 0.0 & 0.0 \\
\hline & Active controls & $60 \pm 0$ & $60 \pm 0$ & 0.0 & 0.0 \\
\hline & Less-active controls & $58 \pm 6$ & $57 \pm 13$ & 1.0 & 1.7 \\
\hline \multirow{3}{*}{$\begin{array}{l}\text { One-leg standing balance test, eyes } \\
\text { closed (s) }\end{array}$} & ACL patients & $33 \pm 22$ & $29 \pm 20$ & 4.0 & 12.1 \\
\hline & Active controls & $31 \pm 20$ & $37 \pm 20$ & -6.0 & -19.4 \\
\hline & Less-active controls & $26 \pm 17$ & $27 \pm 20$ & -1.0 & -3.8 \\
\hline \multirow{3}{*}{$\begin{array}{l}\text { Star excursion balance test, compos- } \\
\text { ite score }(\% \text { leg length })^{\mathrm{a}, *}\end{array}$} & ACL patients & $83 \pm 7$ & $81 \pm 7$ & $2^{\dagger}$ & 2.4 \\
\hline & Active controls & $91 \pm 13$ & $91 \pm 12$ & 0 & 0.0 \\
\hline & Less-active controls & $91 \pm 10$ & $93 \pm 11$ & $-2^{\dagger}$ & -2.2 \\
\hline \multirow[t]{3}{*}{ Single-leg HOP test (cm) } & ACL patients & $139 \pm 28$ & $116 \pm 34$ & $23^{\dagger}$ & 16.5 \\
\hline & Active controls & $137 \pm 34$ & $134 \pm 36$ & 3 & 2.2 \\
\hline & Less-active controls & $128 \pm 43$ & $121 \pm 42$ & $7^{\dagger}$ & 5.5 \\
\hline
\end{tabular}

* Between-group difference $(P<0.05)$

$\dagger$ Between-leg difference within each group $(P<0.05)$

${ }^{\text {a }}$ The composite score is expressed as the mean reaching distance, relative to leg length, of the eight directions

\section{Discussion}

Several previous studies have questioned the validity of using the non-injured leg as a reference for the deficit in neuromuscular function of the injured leg [37, 43, 44]. Our data suggest that the use of the non-injured leg as reference for the injured leg's neuromuscular function is valid except for dynamic balance tests and voluntary quadriceps activation.

\section{Single-joint neuromuscular function}

No bilateral impairments in quadriceps strength were observed despite the reduction in physical activity after the
ACL injury. The absence of bilateral weakness was unexpected because 40 days of detraining can reduce healthy subjects' quadriceps strength by $0.3 \%$ day $^{-1}$ [33] and in ACL patients, bilateral quadriceps strength impairments are still apparent up to 37 days after injury [31]. We suspect the timing of the assessments after the injury is an important factor to detect bilateral quadriceps weakness because we tested ACL patients 208 days post-injury and only found strength impairments in the injured leg.

Activation failure is often cited as a mechanism underlying quadriceps weakness [26, 35] and is observed in ACL patients for as long as 119 days after injury [44]. During the rehabilitation phase, activation deficits decrease over time [39], so it is likely that the injured legs' quadriceps weakness is caused by impaired muscle activation. In contrast to 
Fig. 2 Overall index of neuromuscular function expressed as the mean $\mathrm{z}$-score calculated over all neuromuscular measures. A z-score of zero reflects the mean neuromuscular function pooled across all six legs. ${ }^{\dagger}$ Between-leg difference within each group $(P<0.05)$. Note no bilateral impairments were observed

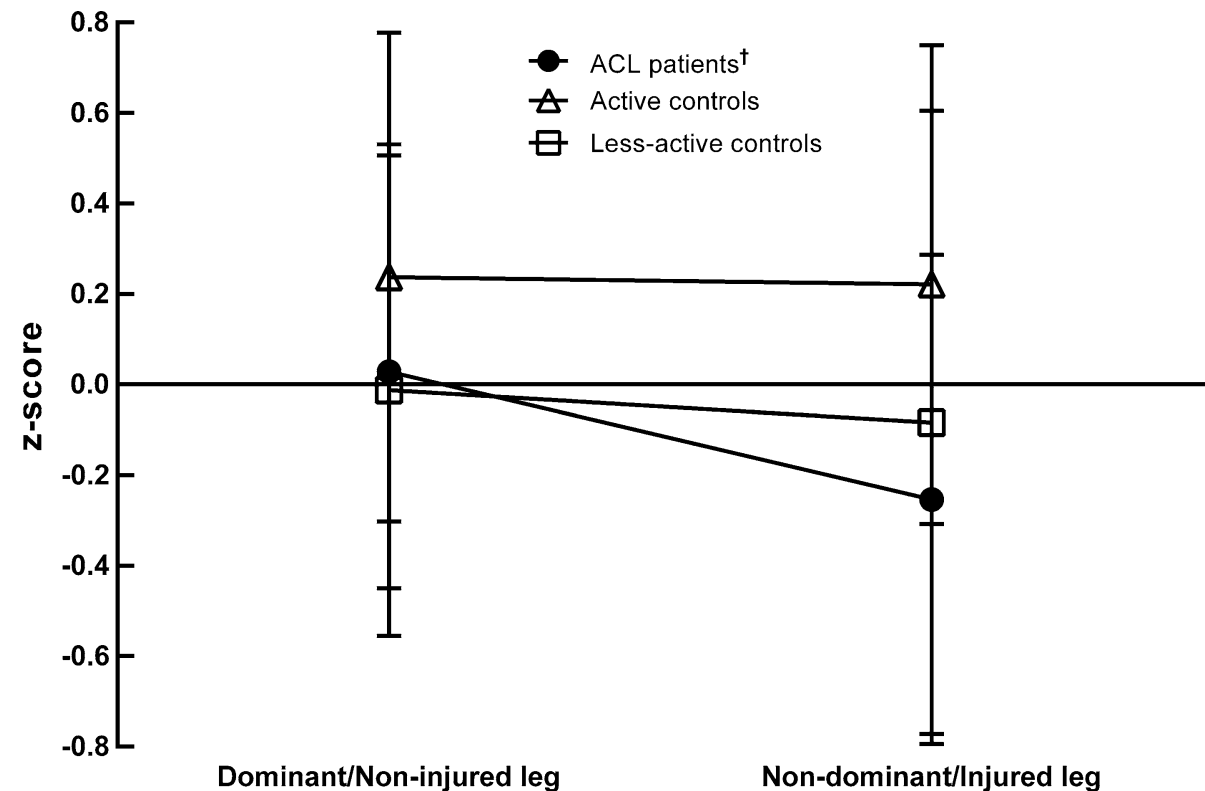

Dominant/Non-injured leg
Non-dominant/Injured leg this, our twitch interpolation data did not provide evidence for an impaired voluntary drive to the quadriceps muscles after 208 days. In addition, the size of the potentiated twitch force did not indicate quadriceps muscle weakness. In addition, the CAR in ACL patients showed a $5 \%$ activation deficit (Table 3), which is much smaller than the $14 \%$ deficit reported 37 days after injury [31]. Our data suggest that quadriceps muscle weakness might be caused by other factors, such as an increase in hamstring coactivation [1], albeit untested in the present study.

Hamstring strength in our ACL patients' injured leg was 9-16\% lower compared with the non-injured leg, which is consistent with previous work [10, 40]. Hamstring strength in the non-injured leg has not been examined previously in the literature, but we found no signs of weakness (Table 2). Hamstring strength appears to be an important regulator of ACL loading during athletic manoeuvres. A $25 \%$ reduction in hamstring strength has been reported to result in a $36 \%$ increase in ACL loading during sidestep cutting [47]. Therefore, the monitoring of hamstring strength should be prioritized to reduce the risk of ACL rupture.

Force control was not affected in ACL patients, which is surprising because previous studies have reported poor force accuracy [36] and variability [6] in patients relative to controls. These impairments in force control were also accompanied by greater hamstring coactivation $[6$, 36]. Other studies also report altered quadriceps activation patterns during a force control task [49-51]. Quadriceps and hamstring electromyogram activity were not measured in the present study, but we expect that muscle activation patterns would have been similar to controls because our ACL patients showed no impairments in force control.
ACL injury did not affect proprioception in either leg. Intuitively, damage to the ACL, a ligament comprising mechanoreceptors that sense the position of the knee joint should affect proprioception [45]. However, our data agree with a recent review suggesting that proprioceptive deficits in ACL patients' injured and non-injured leg are small and not clinically meaningful [18]. Proprioception might remain unaffected due to compensation by mechanoreceptors in and around the knee joint [25] or due to a more prominent role of motor commands when mechanoreceptors in the ACL lack function [38].

\section{Multi-joint neuromuscular function}

SEBT scores were 10-11\% lower in the injured and noninjured leg compared with control legs, where scores on the less challenging static balance test showed no between-leg differences. The SEBT is often used to quantify deficits in dynamic balance in patients with a lower extremity injury, but few such studies included ACL patients [20]. Nonetheless, one ACL study found bilateral impairments in SEBT performance prior to surgery [23], confirming our findings. It has been proposed that bilateral performance impairments can only be detected by tests that greatly stress the knee joint [15]. The SEBT exemplifies such a test, which requires not only muscle strength but also dynamic postural control.

Our study offers new information by examining hop distance prior to surgery; however, hop performance was not impaired in ACL-deficient patients. The hop test is commonly employed following ACL reconstruction, but surprisingly few studies compared the hop distance to controls 
[7, 30, 32]. Two of three studies reported a bilateral reduction in hop distance $[7,30]$, which suggests that bilateral reductions emerge after surgery because we found no bilateral impairments prior to surgery. Nonetheless, our ACL patients jumped $23 \mathrm{~cm}$ ( $0.73 \mathrm{SDs})$ less with the injured versus the non-injured leg, which might be clinically relevant because only small between-leg differences were observed for active $(3 \mathrm{~cm}, 0.09 \mathrm{SDs})$ and less-active $(7 \mathrm{~cm}, 0.17$ SDs) controls.

\section{Active versus less-active controls}

Little is known about how long-term training affects maximal voluntary force and the ability to control submaximal voluntary forces; however, we found no differences in single- or multi-joint neuromuscular functions between active and less-active controls. This is surprising because maximal leg strength was higher in amateur soccer players than sedentary controls [8, 13], and this difference increased with skill level of players [8]. Our less-active controls were still involved in sports although at a lower level, and fewer hours per week. Thus, it might be that our less-active controls were not inactive enough to differ significantly in neuromuscular function from active controls. Further research is needed to provide insights into how training history might affect neuromuscular functions other than maximal leg strength.

\section{Limitations}

Dynamic balance and voluntary quadriceps activation were affected in both legs after ACL injury, but it remains possible that these impairments were already present before the injury. To determine risk factors for ACL rupture, more studies are needed to examine the bilateral neuromuscular and biomechanical function before ACL injury [16, 21, 24] and correlate these with post-ACL injury outcomes.

ACL-deficient patients in the present study were all awaiting surgery but due to several reasons some were operated on sooner than others. Acceptance of and coping with the ACL injury takes time and could have affected our performance outcomes [41]. Although it is common that the time between injury and surgery differs between patients, a more homogeneous group might have resulted in different neuromuscular outcomes [31].

Force control, proprioception, and static balance were not impaired following the ACL injury but modifications in afferent feedback [45] and cortical sensorimotor areas $[3,4,22,29]$ could have prevented these functions from deterioration. Further studies are needed to determine whether these changes in the nervous system are really compensatory mechanisms or are just side effects of the ACL injury.

\section{Conclusion}

Whereas previous studies found bilateral impairments in early stages after an ACL injury, we have found that neuromuscular function, except for dynamic balance and voluntary quadriceps activation, was not impaired in the noninjured leg 208 days after the injury despite the reduction in physical activity following the injury. Therapists should continue to focus on rehabilitating the injured leg following an ACL injury and the non-injured leg can serve as adequate reference to examine the recovery of the injured leg's neuromuscular function.

Acknowledgments This work was supported by a start-up fund from the University Medical Center Groningen. The authors thank BSc. A. Doornbos, BSc. A. Elsinghorst, BSc. G. van der Meiden, BSc. K. Koorenhof, BSc. L. van de Waardt and BSc. L. Winkelhorst for their assistance with the data collection, Prof dr. G. Howatson and dr. J.P. Farthing for checking the manuscript for English, and Medisch Centrum Zuid-Flytta for providing the research facilities.

\section{Compliance with ethical standards}

Conflict of interest The authors report that no conflicts of interest have occurred that are associated with the current study.

Funding This study was supported by a start-up fund from the University Medical Center Groningen.

Ethical approval All procedures performed in studies involving human participants were in accordance with the ethical standards of the institutional research committee and with the 1964 Helsinki declaration and its later amendments or comparable ethical standards.

Informed consent Informed consent was obtained from all individual participants included in the study.

Open Access This article is distributed under the terms of the Creative Commons Attribution 4.0 International License (http://creativecommons.org/licenses/by/4.0/), which permits unrestricted use, distribution, and reproduction in any medium, provided you give appropriate credit to the original author(s) and the source, provide a link to the Creative Commons license, and indicate if changes were made.

\section{References}

1. Alkjaer T, Simonsen EB, Magnusson SP, Dyhre-Poulsen P, Aagaard P (2012) Antagonist muscle moment is increased in ACL deficient subjects during maximal dynamic knee extension. Knee 19:633-639

2. Atwater SW, Crowe TK, Deitz JC, Richardson PK (1990) Interrater and test-retest reliability of two pediatric balance tests. Phys Ther 70:79-87 
3. Baumeister J, Reinecke K, Schubert M, Weiss M (2011) Altered electrocortical brain activity after ACL reconstruction during force control. J Orthop Res 29:1383-1389

4. Baumeister J, Reinecke K, Weiss M (2008) Changed cortical activity after anterior cruciate ligament reconstruction in a joint position paradigm: an EEG study. Scand J Med Sci Sports $18: 473-484$

5. Behm D, Power K, Drinkwater E (2001) Comparison of interpolation and central activation ratios as measures of muscle inactivation. Muscle Nerve 24:925-934

6. Bryant AL, Pua YH, Clark RA (2009) Morphology of knee extension torque-time curves following anterior cruciate ligament injury and reconstruction. J Bone Joint Surg Am 91:1424-1431

7. Chung KS, Ha JK, Yeom CH, Ra HJ, Lim JW, Kwon MS, Kim JG (2015) Are muscle strength and function of the uninjured lower limb weakened after anterior cruciate ligament injury? Two-year follow-up after reconstruction. Am J Sports Med 43:3013-3021

8. Cometti G, Maffiuletti NA, Pousson M, Chatard JC, Maffulli N (2001) Isokinetic strength and anaerobic power of elite, subelite and amateur French soccer players. Int J Sports Med 22:45-51

9. Daniel D, Malcom L, Stone M, Perth H, Morgan J, Riehl B (1982) Quantification of knee stability and function. Contemp Orthop 5:83-91

10. de Jong SN, van Caspel DR, van Haeff MJ, Saris DB (2007) Functional assessment and muscle strength before and after reconstruction of chronic anterior cruciate ligament lesions. Arthroscopy 23:21-28

11. Eitzen I, Holm I, Risberg MA (2009) Preoperative quadriceps strength is a significant predictor of knee function 2 years after anterior cruciate ligament reconstruction. Br J Sports Med 43:371-376

12. Elias LJ, Bryden MP, Bulman-Fleming MB (1998) Footedness is a better predictor than is handedness of emotional lateralization. Neuropsychologia 36:37-43

13. Ergun M, Islegen C, Taskiran E (2004) A cross-sectional analysis of sagittal knee laxity and isokinetic muscle strength in soccer players. Int J Sports Med 25:594-598

14. Flandry F, Hunt JP, Terry GC, Hughston JC (1991) Analysis of subjective knee complaints using visual analog scales. Am J Sports Med 19:112-118

15. Gauffin H, Pettersson G, Tegner Y, Tropp H (1990) Function testing in patients with old rupture of the anterior cruciate ligament. Int J Sports Med 11:73-77

16. Goerger BM, Marshall SW, Beutler AI, Blackburn JT, Wilckens JH, Padua DA (2015) Anterior cruciate ligament injury alters preinjury lower extremity biomechanics in the injured and uninjured leg: the JUMP-ACL study. Br J Sports Med 49:188-195

17. Gokeler A, Welling W, Zaffagnini S, Seil R, Padua D (2016) Development of a test battery to enhance safe return to sports after anterior cruciate ligament reconstruction. Knee Surg Sports Traumatol Arthrosc. doi:10.1007/s00167-016-4246-3

18. Gokeler A, Benjaminse A, Hewett TE, Lephart SM, Engebretsen L, Ageberg E, Engelhardt M, Arnold MP, Postema K, Otten E, Dijkstra PU (2012) Proprioceptive deficits after ACL injury: are they clinically relevant? Br J Sports Med 46:180-192

19. Gribble PA, Hertel J (2003) Considerations for normalizing measures of the star excursion balance test. Meas Phys Educ Exerc Sci 7:89-100

20. Gribble PA, Hertel J, Plisky P (2012) Using the star excursion balance test to assess dynamic postural-control deficits and outcomes in lower extremity injury: a literature and systematic review. J Athl Train 47:339-357

21. Grindstaff TL, Jackson KR, Garrison JC, Diduch DR, Ingersoll CD (2008) Decreased quadriceps activation measured hours prior to a noncontact anterior cruciate ligament tear. J Orthop Sports Phys Ther 38:508-516

22. Grooms DR, Page SJ, Onate JA (2015) Brain activation for knee movement measured days before second anterior cruciate ligament injury: neuroimaging in musculoskeletal medicine. J Athl Train 50:1005-1010

23. Herrington L, Hatcher J, Hatcher A, McNicholas M (2009) A comparison of star excursion balance test reach distances between ACL deficient patients and asymptomatic controls. Knee 16:149-152

24. Hewett TE, Myer GD, Ford KR, Heidt RS Jr, Colosimo AJ, McLean SG, van den Bogert AJ, Paterno MV, Succop P (2005) Biomechanical measures of neuromuscular control and valgus loading of the knee predict anterior cruciate ligament injury risk in female athletes: a prospective study. Am J Sports Med 33:492-501

25. Hogervorst T, Brand RA (1998) Mechanoreceptors in joint function. J Bone Joint Surg Am 80:1365-1378

26. Hopkins JT, Ingersoll CD (2000) Arthrogenic muscle inhibition: a limiting factor in joint rehabilitation. JSR 9:135-159

27. Hortobagyi T, Garry J, Holbert D, Devita P (2004) Aberrations in the control of quadriceps muscle force in patients with knee osteoarthritis. Arthritis Rheum 51:562-569

28. Hortobagyi T, Tunnel D, Moody J, Beam S, DeVita P (2001) Low- or high-intensity strength training partially restores impaired quadriceps force accuracy and steadiness in aged adults. J Gerontol A Biol Sci Med Sci 56:B38-B47

29. Kapreli E, Athanasopoulos S, Gliatis J, Papathanasiou M, Peeters R, Strimpakos N, Van Hecke P, Gouliamos A, Sunaert S (2009) Anterior cruciate ligament deficiency causes brain plasticity: a functional MRI study. Am J Sports Med 37:2419-2426

30. Larsen JB, Farup J, Lind M, Dalgas U (2015) Muscle strength and functional performance is markedly impaired at the recommended time point for sport return after anterior cruciate ligament reconstruction in recreational athletes. Hum Mov Sci 39:73-87

31. Lepley AS, Gribble PA, Thomas AC, Tevald MA, Sohn DH, Pietrosimone BG (2015) Quadriceps neural alterations in anterior cruciate ligament reconstructed patients: a 6-month longitudinal investigation. Scand J Med Sci Sports 25:828-839

32. Mattacola CG, Perrin DH, Gansneder BM, Gieck JH, Saliba EN, McCue FC III (2002) Strength, functional outcome, and postural stability after anterior cruciate ligament reconstruction. J Athl Train 37:262-268

33. Narici MV, Roi GS, Landoni L, Minetti AE, Cerretelli P (1989) Changes in force, cross-sectional area and neural activation during strength training and detraining of the human quadriceps. Eur J Appl Physiol Occup Physiol 59:310-319

34. Negahban H, Mazaheri M, Kingma I, van Dieen JH (2014) A systematic review of postural control during single-leg stance in patients with untreated anterior cruciate ligament injury. Knee Surg Sports Traumatol Arthrosc 22:1491-1504

35. Palmieri-Smith RM, Thomas AC, Wojtys EM (2008) Maximizing quadriceps strength after ACL reconstruction. Clin Sports Med 27:405-424

36. Perraton L, Clark R, Crossley K, Pua YH, Whitehead T, Morris $\mathrm{H}$, Telianidis S, Bryant A (2016) Impaired voluntary quadriceps force control following anterior cruciate ligament reconstruction: relationship with knee function. Knee Surg Sports Traumatol Arthrosc. doi:10.1007/s00167-015-3937-5

37. Pietrosimone B, Lepley AS, Harkey MS, Luc-Harkey BA, Blackburn JT, Gribble PA, Spang JT, Sohn DH (2016) Quadriceps strength predicts self-reported function post-ACL reconstruction. Med Sci Sports Exerc 48:1671-1677

38. Smith JL, Crawford M, Proske U, Taylor JL, Gandevia SC (2009) Signals of motor command bias joint position sense in 
the presence of feedback from proprioceptors. J Appl Physiol 106:950-958

39. Snyder-Mackler L, De Luca PF, Williams PR, Eastlack ME, Bartolozzi AR III (1994) Reflex inhibition of the quadriceps femoris muscle after injury or reconstruction of the anterior cruciate ligament. J Bone Joint Surg Am 76:555-560

40. St Clair Gibson A, Lambert MI, Durandt JJ, Scales N, Noakes TD (2000) Quadriceps and hamstrings peak torque ratio changes in persons with chronic anterior cruciate ligament deficiency. J Orthop Sports Phys Ther 30:418-427

41. te Wierike SC, van der Sluis A, van den Akker-Scheek I, Elferink-Gemser MT, Visscher C (2013) Psychosocial factors influencing the recovery of athletes with anterior cruciate ligament injury: a systematic review. Scand J Med Sci Sports 23:527-540

42. Tegner Y, Lysholm J (1985) Rating systems in the evaluation of knee ligament injuries. Clin Orthop Relat Res 198:43-49

43. Urbach D, Awiszus F (2002) Impaired ability of voluntary quadriceps activation bilaterally interferes with function testing after knee injuries. A twitch interpolation study. Int J Sports Med 23:231-236

44. Urbach D, Nebelung W, Weiler HT, Awiszus F (1999) Bilateral deficit of voluntary quadriceps muscle activation after unilateral ACL tear. Med Sci Sports Exerc 31:1691-1696

45. Valeriani M, Restuccia D, Di Lazzaro V, Franceschi F, Fabbriciani C, Tonali P (1996) Central nervous system modifications in patients with lesion of the anterior cruciate ligament of the knee. Brain 119(Pt 5):1751-1762
46. Verkerke GJ, Lemmink KA, Slagers AJ, Westhoff MH, van Riet GA, Rakhorst G (2003) Precision, comfort and mechanical performance of the Quadriso-tester, a quadriceps force measuring device. Med Biol Eng Comput 41:283-289

47. Weinhandl JT, Earl-Boehm JE, Ebersole KT, Huddleston WE, Armstrong BS, O'Connor KM (2014) Reduced hamstring strength increases anterior cruciate ligament loading during anticipated sidestep cutting. Clin Biomech (Bristol, Avon) 29:752-759

48. Wiggins AJ, Grandhi RK, Schneider DK, Stanfield D, Webster KE, Myer GD (2016) Risk of secondary injury in younger athletes after anterior cruciate ligament reconstruction: a systematic review and meta-analysis. Am J Sports Med 44:1861-1876

49. Williams GN, Snyder-Mackler L, Barrance PJ, Buchanan TS (2005) Quadriceps femoris muscle morphology and function after ACL injury: a differential response in copers versus noncopers. J Biomech 38:685-693

50. Williams GN, Barrance PJ, Snyder-Mackler L, Buchanan TS (2004) Altered quadriceps control in people with anterior cruciate ligament deficiency. Med Sci Sports Exerc 36:1089-1097

51. Williams GN, Barrance PJ, Snyder-Mackler L, Axe MJ, Buchanan TS (2003) Specificity of muscle action after anterior cruciate ligament injury. J Orthop Res 21:1131-1137 